Articles

8-2012

\title{
Faculty as Learners: Developing Thinking Communities
}

Pamela L. Eddy

College of William \& Mary, pamela.eddy@wm.edu

Regina L. Garza Mitchell

Texas State Technical College - Harlingen, regina.garza-mitchell@harlingen.tstc.edu

Follow this and additional works at: https://scholarworks.wm.edu/articles

Part of the Educational Leadership Commons, and the Higher Education Commons

\section{Recommended Citation}

Eddy, Pamela L. and Garza Mitchell, Regina L., "Faculty as Learners: Developing Thinking Communities" (2012). Articles. 64.

https://scholarworks.wm.edu/articles/64

This Article is brought to you for free and open access by W\&M ScholarWorks. It has been accepted for inclusion in Articles by an authorized administrator of W\&M ScholarWorks. For more information, please contact scholarworks@wm.edu. 


\section{Faculty as Learners: Developing Thinking Communities}

Abstract

The shifting demographics of faculty ranks, expansion of faculty work, and the press for accountability and revenue production place new demands on today's faculty. Collaborating with other faculty members is one option for easing workload demands and reinvigorating faculty members as they approach their teaching and research. This article discusses the importance of collaboration among faculty in deriving new strategies for the classroom and approaches to research, and it provides suggestions for moving beyond short term collaborations and toward the creation of thinking communities that have the potential to re-energize faculty and bring passion back to their work. 
Faculty work has received heightened attention over the past decade. First, the composition of faculty ranks is shifting with more part-time and contingent faculty members teaching in today's colleges and universities. Second, the actual day-to-day work functions of faculty members have expanded over time due to shifts in teaching practices, disciplinary norms, and globalization trends. Indeed, the average number of hours worked by faculty each week has consistently increased since 1984, with the average faculty member working 49 hours per week in 1998; at that time, it was also reported that the number of faculty working more than 50 hours per week had doubled since 1972 (Schuster \& Finkelstein, 2008). Today, there are fewer fulltime faculty members working more hours and covering expanded roles.

Coupled with these classroom-based shifts in work are organizational pressures that leave institutions with fewer resources, changing student demographics and student demands, and public calls for increased accountability on outcomes. Gappa, Austin, and Trice (2007) point out that changes in faculty demographics and expanded demands on faculty time result in a need to rethink the composition of faculty work. The authors posit five key elements critical to faculty work, namely equity, academic freedom, flexibility, professional growth, and collegiality. Even though these points begin to address central elements necessary for faculty to be successful, they do not account for the ever increasing demand on faculty time and the feeling of constraint experienced by faculty members (O’Meara, Terosky, \& Neumann, 2008). Shifts in faculty work have led to an increased need for faculty to garner research funding and other support in addition to regular teaching, service, and research duties. The increased workload demands can lead to dissatisfaction with the faculty role and a lag in productivity. Thus, there is a need to approach faculty work in a way that will attract new faculty members from the ranks of doctoral students and revitalize those already in the ranks. 
From a faculty development perspective, collaborating with other faculty members is one option for easing workload demands and for reinvigorating faculty members as they approach their teaching and research (Pifer, 2010). This article discusses current expectations for faculty members and the importance of collaboration among faculty to come up with new strategies for the classroom and approaches to research, and it provides suggestions for moving beyond short term collaborations and toward the creation of thinking communities that have the potential to reenergize faculty and bring passion back to their work. Finkelstein (1982) argued that faculty have particular collegial needs and ultimately defined five specific areas in which faculty desire support: 1) help in teaching; 2) help in research; 3) institutional linkage; 4) linkage to the discipline; and 5) general support, intellectual stimulation, and friendship (pp. 15-16). Further, he found links between levels of colleagueship and research productivity. Yet, despite these findings, a generation later, faculty still struggle with these issues and desire heightened colleagueship and connections (Pifer, 2010).

Thinking communities may provide an opportunity to meet some of the current demands facing faculty. These communities are reflective spaces intentionally developed by faculty members to create a synergy for knowledge creation. Faculty Learning Communities (FLC) are another mechanism used by faculty members to create a joint learning space, but thinking communities differ in several ways. First, the typical arrangement of FLCs uses a yearlong program guided by a curriculum (Cox, 2004), whereas thinking communities are not grounded in a formal process. Second, the organization of FLCs usually involves a specific cohort of faculty (for example, new faculty) or revolves around a particular topic. Both of these organizational frameworks are temporal in nature and do not address the ongoing nature of thinking communities. Both FLC and thinking communities involve faculty learning, but accomplish this 
outcome through different means. Yet, even with these differences, a thinking community may emerge over time from initial interactions established within a FLC.

Student learning communities also provide a forum for comparison. Often, student learning communities target struggling students using a structured support network. Recent research on the learning outcomes of students participating in a learning community for developmental math, for instance, found that students in a learning community attempted and passed their classes at higher rates than those not participating, but that the positive effect of participation in the learning community did not result in persistence or completion (Weissman, Butcher, Schneider, Teres, Collado, \& Greenberg, 2011). Similarly, Russ (2010) discovered that underprepared students obtained significantly higher achievement rates, reported higher levels of social and academic integration, and declared intentions to persist. Like faculty learning communities, those designed for students are structured and of a limited duration. The benefits of collaborative learning are apparent, but in the case of students, the outcomes target particular levels of achievement. Longer term collaboration is not evident.

The group process of a thinking community moves beyond mere contribution to joint projects and toward the establishment of a true cooperative in which tallying of contributions does not exist and lines blur regarding attribution of solo ideas or individual writing attributions. Instead, a space is created that nurtures creativity and enhances knowledge production via questioning of underlying assumptions. The process of thinking in a group allows faculty members to re-engage in the learning process, and places an emphasis on reflection, providing a greater connection to their students, and aids in removing the isolation of solo teaching. Brookfield (1995) emphasized the importance of faculty reflection as a means to improve 
teaching. This type of reflection serves as a critical linchpin (Schon, 1983) and point of distinction for thinking communities.

\section{Faculty Work}

Changes in faculty work have developed over time and exemplify changes in the external environment. In particular, faculty work is impacted by the economy, technology, political, and business factors. Sorcinelli, Austin, Eddy, and Beach (2006) chronicled shifts in professional development by identifying Five Ages of Faculty Development, in which each era showcases changes in emphasis of faculty work. The Age of the Scholar, spanning the 1950s and 1960s represents a period in time that focused on developing faculty expertise as scholars. The faculty role of researcher was emphasized. As the student body changed during the 60 s and 70 s, a new focus on instructional improvement emerged resulting in the Age of the Teacher. The Age of the Teacher turned attention to developing classroom skills. This era (late 1960s and 1970s) witnessed a time of faculty retrenchment and a resulting need to reinvigorate faculty members. The focus on teaching also helped address shifts in thinking about curriculum and program delivery and addressed student demands for changes in teaching practices. The traditional view of faculty work in which faculty members are expected to be scholars and researchers foremost expanded to include classroom outcomes. During the 1980s, institutions experienced a decline in budget and changes in academic life, but also saw an upsurge in the establishment of faculty development centers leading to the Age of the Developer. Major foundations provided funding to start centers to help jump-start faculty vitality and to explore how to improve undergraduate teaching. On the heels of this era came the Age of the Learner (1990s). Here, focus shifted to helping support student-centered learning, meeting the needs of diverse learners, and incorporating technology into classroom teaching. Finally, the current era, the Age of the 
Network, developed with the new millennium and connects several of the strands of previous eras.

The roots of the various eras outlined above emerge from Boyer's (1990) concept of scholarship. He concluded that multiple forms of scholarship exist for faculty including the scholarship of discovery, scholarship of integration, scholarship of application, and scholarship of teaching. Instead of viewing faculty work as a choice between the various forms of faculty work, he argued for increased integration and value associated with the various forms of scholarship.

Despite Boyer's (1990) argument for multiple forms of scholarship, the essence of a dichotomy between teaching and research persists. Arreola, Theall, and Aleamoni (2003) posit instead the need for a view of the professoriate as a meta-profession in which their model "clarifies the relationship between faculty evaluation programs, faculty development programs, and the assumptions underlying their structure and operation" (p. 1). This model provides a more complex way to think of the links between reward systems, faculty work, and development programs. What this model does not account for, however, is how collaborative work is valued. The multiple roles of expertise required of faculty still remains vested in singular efforts. As faculty roles have expanded, the need for collaboration and connections to meet increased requirements on faculty time takes on heightened importance. A question remains about how faculty development offices, and colleges overall, can best support faculty members in developing networks that lead to successful collaboration efforts.

The last 20 years, in particular, are witness to a movement toward a greater focus on learning, particularly for undergraduate students (Boyer, 1987; Pacarella \& Terenzini, 2005). Technology has certainly been the greatest influence on faculty work in recent years providing 
new methods for teaching and learning, conducting research, administration, and other aspects of faculty work. In the Age of the Network, technology has enabled faculty work to expand to meet heightened expectations that often require collaborative efforts among many stakeholders in higher education. Collaborative work is not always valued highly in terms of tenure and promotion, but there is often a need to collaborate in order to attain research funding, to complete large projects, and to develop interdisciplinary teaching opportunities (Hart \& Mars, 2008;

Lattuca, 2001). While collaboration is often used as a means toward an end, it also provides the benefits of synergy and an expanded knowledge base when approached intentionally (Amey \& Brown, 2004).

\section{Shifting Sands of Collaboration}

Collaborations exist at multiple levels and are looked upon differently depending on the field of study. Hart and Mars (2008) used the cultural lens of academic tribes, which describes how disciplines have different norms and values that guide expectations, to describe how faculty with joint appointments faced the dualities of their positions. They found that tensions around professional identity and concerns over the tenure and promotion process detracted from the benefits accrued by crossing disciplinary borders. The burdens faced by these faculty members mirror those in other forms of collaborations, namely justifying professional work and bridging between academic cultures. In the sciences, research collaborations are increasingly the norm as funding for labs and scientific research relies on the attainment of external funding that encourages and rewards faculty collaboration. Yet, even in areas where collaboration is expected, faculty members often have to defend their participation in collaborative teaching or research projects. In regard to tenure and promotion, the notion of collaboration becomes tied to the perceived level of contribution. Collaboratively teaching between disciplines may have an 
impact on how teaching assignments are tracked and accounted (Lattuca, 2001). The importance of individual contributions also carries over to authorship of collaborative manuscripts or joint teaching. A faculty member is deemed more important, and therefore contributing more to the group, if her or his name appears first on an article or the faculty is the lead faculty for the course. Thus, collaboration becomes competition and remains focused on the individual as those involved strive to demonstrate their perceived importance to the group. Conversations about authorship often present underlying assumptions of power and prestige within a group (Morgan, 2006). For example, a faculty running a lab or center may require that their name appear first in the author listing ahead of graduate students or junior faculty (McGinn, Shields, ManleyCasimir, Grundy, \& Fenton, 2005). More formalized tenure and promotion policies can begin to address the codifying of joint efforts.

In this view, then, collaboration serves as a means for producing a distinct product such as a research paper or a grant proposal and may be viewed as detracting from solo endeavors. The output of collaboration is viewed as a commodity of faculty productivity and valued differently than a solo authored piece of research or a single standalone class. Collaborations are instigated because each member of the partnership or group brings something of value to the project, and that knowledge base is later accessed by others. Thus, individual contributions to a project become a form of currency within a traditional definition of collaboration that may value one form of contribution over another. Knowledge, expertise, and other types of work are exchanged as transactions for opportunities that benefit participants individually, and benefits are realized in a tangible sense. Yet it is evident that a number of motivations and outcomes exist for long-term faculty collaborations. Creamer (2004) noted four distinct outcomes of long-term collaborations, namely efficiencies of practice, nuances in thinking, coming up with the big 
picture, and challenging the gospel (p. 35). In Creamer's study, the majority of long-serving collaborations focused on more than mere outcomes and instead relied on benefits accrued during the process of collaboration. The bottom line was that collaborators were able to accomplish more together than they would have on their own.

Traditional collaborations involve working together until an end result is achieved, or in some cases, collaborations may continue with multiple projects that emerge from the initial joint venture. Good collaborations continue over time because of a developing synergy between group members. The group becomes not only a place to work but a place that inspires creativity, productivity, and energy that reinvigorates the idea of work. These longer-term collaborations provide the additional benefit of placing the faculty member in the role of learner, a role which is all too often overlooked once we become "expert" in our field. As faculty engage in collaborations, they are pushing their own understanding about material as a result of the interactions and helping to advance knowledge creation.

When thinking communities develop, the underlying foundation of faculty collaboration shifts from product to process and a change occurs in which a unique thinking space is created for participants. The synergy involved in the group process also alters over time given faculty members' positions along the career pipeline that values production for tenure and promotion to one that focuses on reigniting the passion of faculty work. The group process involves creating a framework in which all members can contribute, establishing a space in which joint work occurs-both in a physical sense by meeting together, but also in an intellectual sense as well, and forming protocols that outline group. expectations and help build trust among members. Group participation becomes easier as faculty obtain higher rank. Full professors need not worry over how publications or teaching count for promotion or tenure and may see collaborations as a 
means to reinvigorating their work. Because the focus is no longer on product, higher ranked faculty members are not time constrained and have the luxury of being able to appreciate the process (Hinck et al., 2009). Struggles may remain for junior faculty involved in these collaboration and dialogue needs to occur to assure a common set of understandings over expectations and an agreement regarding the ebbs and flows of individual contributions (Austin \& Baldwin, 1991). Ultimately, the creation of thinking communities can enhance the collaborative process and begin to address issues of power imbalance, alignment of multiple forms of scholarship, and building of creative spaces for faculty work.

\section{Thinking Community Model}

It is helpful to think about the development of thinking communities as a progressive process. John-Steiner (2000) used the term "thought community" to refer to "experienced thinkers who collaborate with an intensity that can lead to a change in their domain's dominant paradigm" (p. 196). Thinking communities develop over time and can be a natural evolution of long-term group collaboration. However, there are distinct differences between joint projects or collaborative groups and thinking communities. Collaborations are long or short-term, form around a common goal, and hinge upon some type of end product. Likewise, communities of practice are defined as "groups of people who share a concern or a passion for something they do and learn how to do it better as they interact regularly" (Wenger, 2006, para. 3). The key difference between a joint project, collaboration, or community of practice and a thinking community concerns the main focus of the group.

The primary focus of a joint project or collaboration centers around an end product. The goal is to produce a tangible output, whereas the focus of a community of practice is to improve an end product. In both cases, it is efficiency and final results that are the focus. Faculty learning 
communities represent one form of a community of practice with their focus on a specific facet of faculty work (Cox, 2004). While products may result from a thinking community, the primary focus of a thinking community remains on process, deconstruction of current knowledge, and intellectual exploration by group members. These communities often produce tangible outputs, but the process and space are most critical for the involved faculty. We have developed a model to illustrate the evolution of thinking communities. The model (see Figure 1) illustrates the progression from simple joint projects to collaborations to ultimately a thinking community and outlines key features of each stage.

\section{INSERT FIGURE 1 ABOUT HERE}

In a thinking community, the group and its processes evolve purposefully through intentional reflection, both at the individual and group levels. Collaboration in a thinking community adds “a third dimension, a deeper view, to [group members'] knowledge of themselves" (JohnSteiner, 2000, p. 63), which allows group members to assume a perspective outside of their own conception. These thinking communities have the potential to transform understanding in their fields and shift established paradigms of knowledge through the questioning of underlying assumptions and reflection on practices.

\section{Joint Project}

Many collaborations stem from a pair or a group of people who agree to work together on a project. This type of association generally involves two or more people combining individual efforts that result in a mutually beneficial product that is on a timeline for completion. The project may involve guest lectures in alternative faculty member's classes or collaboration on the 
creation of a new course or a major overhaul of an existing course. Research joint projects may involve collaborating on a single project or writing a research manuscript. These collaborations are often short-term and cease when the project is completed. If the project outcomes are satisfactory and if the faculty members find that their work complements each other, they may choose to either extend the project or to work on something else together. Over time trust develops and the joint project may progress into a focused collaboration between two or more people in which the work becomes less individualistic and centers around shared outcomes.

\section{Collaboration}

If a joint project works well, then it may progress into a more established collaboration in which ideas are exchanged freely, and the scope of teaching and research expands. This type of collaborative stems from shared outcomes that develop through discourse among group members. Collaborations of this type still tend to be term limited and product-oriented, but they have the potential to result in greater discourse around issues of interest to the group. A collaboration requires greater investment from group members in terms of time, effort, and trust. Collaborations occur because of mutual interest in a final product or products, but the amount of trust involved is greater than that of a joint project as ideas belong to and are shared by the group. Collaborations may also result in communities of practice, in which people work together to learn how to improve a practice or product (Wenger, 2006) or emerge from FLC (Cox, 2004) focused projects. When the scope of collaboration expands, the number of members in the group may also expand as collaborators tap into their own networks and invite greater participation. For instance, an interdisciplinary course may initially involve only two faculty members from different departments, but eventually expand to include multiple faculty and other departments. 
Likewise, a collaboration of research partners may grow to include others with complementary disciplinary contributions.

\section{Thinking Community}

Thinking communities evolve when groups move beyond product orientation and focus instead on the reflective process that includes changes in the way group members think or perceive what they know. While we may argue that all of us in academe are experienced thinkers, the deliberate nature of a thinking community results in a willingness to share and expand personal schemas (Senge, 1990) to fit new conceptions and understandings. Rather than viewing issues through a single lens, a thinking community examines the issue through a variety of angles in order to better understand the problem and to enhance one's own thought processes. A thinking community functions as a means for expanding the role of faculty as learners.

Thinking communities, then, are a means of enhancing faculty learning rather than simply a means of increasing or improving output. From a learning perspective, a thinking community promotes double-loop learning (Argyris \& Schon, 1978; Schon, 1983) in which feedback loops operate internally through deliberate self- reflection and externally through reflection within a group. In this regard, thinking communities focus on the process of creation (i.e., learning) as opposed to a sole focus on product.

\section{Characteristics of Thinking Communities}

Central to the development of a thinking community are changes in dominant or hegemonic thought schemas. Senge (1990) refers to mental maps that guide our thinking, but which may also preclude individuals from seeing alternatives unless they reflect upon underlying assumptions (Argyis \& Schon, 1978). Involvement of individuals with diverse guiding epistemologies aids in prompting group members to question their own understanding of 
knowledge by deconstructing ideas and exploring new areas of thought. A caution exists at this point, however, as differentials in power may preference certain perspectives. Attention to underlying power inequities (Austin \& Baldwin, 1991) becomes a part of the group reflective process to aid in recognizing these issues. Differences in group members' position, expertise, and individual power may create tensions in a thinking community if the roles of power and privilege remain unaddressed.

Greater focus on process, and less on product, invites group members to be more open in their collaboration because they move past merely thinking of the next product or teaching the next class. Junior faculty, however, may find that tenure requirements create pressures for products, namely publications and grant funding, and as a result may have to reconcile the tradeoffs in their involvement in longer-term thinking communities in which tangible products are not immediate or aligned with the tenure clock. Although there is a focus on the group process, this emphasis does not mean that products do not exist or that they are not important to the group. Products do emerge from the collaborations of thinking communities, but instead of being the primary goal, they are a significant byproduct of the thinking community. Rather, by shifting attention to the process within the group, questioning of group members' underlying theoretical frameworks and schemas allows for deeper exploration of ideas and potentially creates new ways of thinking. This process can result in transformational learning (Mezirow \& Taylor, 2009) for members - shifting how faculty think about what they know, a distinct difference from a collaboration in which the goal is to learn more about a single element, such as a research project, or realm, as in a community of practice (Lave \& Wenger, 1991) . A thinking community results in meta-analysis of process and the questioning of disciplinary assumptions (Creamer, 2004). 
The initial formation of a thinking community might emerge from a successful joint venture or collaboration. As well, a thinking community could develop based upon relationships originally formed within a community of practice (Lave \& Wenger, 1991) or FLC (Cox, 2004). Faculty members seeking to develop a thinking community may look to their existing collaborators and colleagues as a source of membership for creating this type of group. Essential in this group formation are articulated and shared values to guide the group process and a commitment to ongoing reflection. Likewise, institutions can spur on the creation of thinking communities by creating a framework that fosters this type of group formation. Seed grants can help jumpstart this process by producing an opportunity for faculty to have time to devote to the effort. As well, specific language in tenure and promotion policies that values collaborative work could serve to reward faculty for group participation and ventures.

Thinking communities develop several critical characteristics that contribute to success within the group process. Group members are focused on learning and expanding their understanding of ideas. In that regard, the group may set aside time for individual journaling on a given topic and later discuss what each group member wrote, or the group may approach a project together and then share their thoughts on how each group member approached the project, what their guiding assumptions were, and why those assumptions were held. It is the two-step process of reflecting individually (what do I think and why?) combined with the group discussion of similarities and differences (how did others think differently about this and how does this impact my own thinking?) that allow group members to understand, and possibly alter, their modes of thinking. Here, concepts of lifelong learning and adult learning theories contribute to understanding of the interactions within the group. Central to the learning process is the idea of tying new learning to past experience, in this case disciplinary knowledge, and self-directed 
learning guides the faculty members. Members engage in critique and develop a shared vision of the function of the group. They privilege the time dedicated to the thinking group, which can be as simple as making all group meetings and contributing to the process. These traits do not emerge instantaneously when the group forms, yet develop over time as trust within the group grows.

As noted by Creamer (2004), long-term collaboration involves dedication to the group. Commitment to meeting regularly and holding group work time as sacrosanct builds trust and relationships among group members, another important element of thinking communities. Dedication to the group process also allows for the creation of shared meaning of goals and vision for the thinking community as well. As in all types of team work, norms are established in which members feel safe to criticize and critique one another to help advance the process. Yet, addressing imbalances in power among group members must occur. Tensions can emerge if group members do not have a system for discussing how to handle disagreements, if members with more power due to rank or longevity on campus take over, or if individual goals and objectives do not align with the group vision. Issues may arise when a member of the thinking community is not an active participant and does not contribute. In this instance, the lack of involvement may be episodic due to other personal or professional demands and the member may become reengaged. Yet, long-term detachment and lack of involvement by an individual can disrupt group dynamics and must be dealt with by group members.

At times, thinking communities might have a champion of the process, but at other times various group members take on leadership roles. Thinking communities are not always egalitarian, but they are based on the value of all members' contributions regardless of their roles or positions. Initially, some hierarchies might exist in a group, particularly one formed when an 
individual is a graduate student working with a team led by a faculty member (Hinck, et al., 2009). To avoid potential problems, group members should address hierarchical issues at the onset of the groups by considering power differentials that may exist due to gender, rank, or other factors, and how potential problems of members feeling inferior or superior may be avoided. Once hierarchical elements are recognized, group rules may be established to ensure all members are provided equitable input and consideration. For example, the group may choose to have a different person lead the group reflection time, or members may be assigned to oversee different tasks. The greatest means of avoiding issues resulting from group member's unequal power is to develop relationships in which each group member is considered individually rather than through their rank, position, or discipline. When a group member feels that undue power of one member is influencing the group process, it is imperative to have a process in place to discuss these issues. Over time, as relationships strengthen, these hierarchical distinctions blur to allow for more ebbs and flows in leadership within the group.

One key milestone for faculty is the tenure and promotion process. New faculty members in particular have concerns regarding what they often perceive as a confusing and unarticulated pathway to tenure (Gappa et al., 2007; Sorcinelli, 2000, 2002). Due to the pressures present in the tenure process, faculty members may be reluctant to take part in collaborative work that they do not know how will be valued by review committees or departmental colleagues. Here, institutions can provide clarity in tenure and promotion policies that indicate how collaborative work will be counted in the process. Faculty members can then create tenure and promotion narratives that showcase how their collaborative work has advanced knowledge within their disciplines, in particular how preconceived knowledge and scholarship is challenged and thinking expanded (Creamer, 2004). 
Defining group processes and knowing the goals of thinking communities is important in establishing a thinking community. Group processes involve basic elements of team building and creation in which members understand their individual responsibilities toward the group and patterns of behavior within the group. For some, initial collaborative efforts may eventually shift to the creation of a thinking community. In this instance, working together over time creates a sense of shared purpose and value of time working together, collaborators know whom they can trust to follow through on aspects of projects, and individuals become open to questioning their own underlying assumptions. Intentionally seeking to establish a thinking community requires a few key steps. First, identification of an area of inquiry for research must occur through open discussion among group members. The focus may be on project specific areas such as researching a particular ecosystem, addressing a social issue such as college access for lowincome students, or inquiring about the historical significance of the beginning of social movements. Another important element in the formation stage is purposeful inclusion of individuals who may look at the central issue differently. These different perspectives may be due to disciplinary differences or may be because of alternative methodological approaches. The advantage of seeing a problem from multiple perspectives provides the central benefit to this type of group. Finally, a process for individual and group reflection must be included in the guiding principles for the thinking community.

\section{Sustaining Momentum and Keeping it Together}

Thinking communities develop over time with intentional effort. Fostering a community that values the process of generating ideas forces group members to dig deeply into long-held assumptions and encourages new methods of learning, and mutual gains arise through group processes. Reflection is a key element in this process (Schon, 1983). Although the benefits are 
many, one major challenge remains, the same issue that ensues in any type of collaborative work: the means for sustaining long term work as a community.

Faculty development programming can support faculty work in thinking communities. First, faculty development programming can create space, both physical in use of conference rooms in the faculty development center and temporal in the creation of time for faculty to meet to collaborate. Second, programming can review tactics central to group processes, such as how to establish group norms, discussion of communication practices, and training for dealing with conflict. Finally, faculty development leaders can work with institutional leaders to develop policies for tenure and promotion that acknowledge and value the collaborative process.

Sustainability of the group requires that members benefit from their involvement within the thinking community. Benefits, however, may mean different things for different members. For some, a benefit is having a space that feels safe for testing out new ideas or having their concepts challenged and ultimately improved, whereas for others the group provides a professional network that shifts understanding of disciplinary knowledge. If institutional policies are in place that codify participation in collaborative work in tenure and promotion reviews, individuals seeking these key faculty milestones may obtain benefits in a tangible manner. Members must also have comfort with uncertainty, as the outcomes of the thinking community are unknown and often unpredictable. Individual and group learning often takes serendipitous routes that result in benefits for all members of the group, but these benefits are difficult to predict. As noted above, however, thinking communities are not without outcomes; products in the form of new courses, creation of interdisciplinary degrees, publications, presentations, and grants result from the group process even though the process of the thinking community is 
central. These scholarly products can translate directly to positive contributions in a tenure or promotion dossier.

Structured time is another necessary element of sustaining a thinking community. Trust is created through time spent together, open communication, and shared understanding. FLC use this tactic to allow faculty to address an issues in a time bound fashion, typically an academic year (Cox, 2004). What FLCs and communities of practice build upon is the fact that relationship building takes time. Likewise, nurturing trust requires time, and group members must be willing and able to spend that time together. Typical faculty schedules offer summers as an opportunity for focused group work; national or international conferences also provide times when individuals from different institutions can have face-to-face time for group gatherings. However, a thinking community can only develop through regularly scheduled time for interaction and communication. Technology provides a growing number of means for collaborative work to occur and for supplementing communication among members. Faculty members with access to a learning management system can create a virtual space that allows the group to span the space and time continuum. Audio and video conferencing create links for realtime connections for the group. More faculty members are using social networking sites, such as Facebook, that also allow them to communicate when schedules may not mesh. Wiki and blog sites are alternate spaces where faculty members may collaborate. These systems provide a place for multiple individuals to work together through sharing ideas synchronously or asynchronously. The benefit to incorporating technology is that it also provides a means to track individual learning and changes over time. This article, for instance, was written collaboratively using a wiki. When looking at changes over time, it is apparent that the writing was a joint effort as few sentences can be attributed to one author. This format aids in removing the risk of feeling 
like a single person has responsibility for the final writing and begins to level power differentials.

Critical reflection is the most important component in sustaining thinking communities. Meta-cognition, thinking about thinking, provides a central element of learning by requiring faculty members to question assumptions about their thinking. Meta-cognition allows a person to understand their own cognitive processes (Flavell, 1976), which leads to understanding and processing information in ways that help us step outside of our preferred and usual schemas. In a group format, intentional reflection in this manner helps us also understand the way that others process information. Intentional reflection is key to the learning process and in encouraging faculty to think differently. When faculty are learners, their own ideas as well as those in the group, are able to advance in the process. Ongoing reflection provides a means of generating feedback about learning into the group process and individual faculty thinking processes, helps group members assess benefits, contributes to long term sustainability of the thinking community, and reawakens faculty members as learners.

\section{Conclusion}

Individuals are initially drawn to faculty work due to a passion regarding their scholarly interests (Neumann, 2009). Training for the professoriate, however, focuses on the individual pursuit of knowledge and the defense of new ideas. New faculty members are often surprised by the levels of isolation faced when they obtain their first positions in academe (Menges, 1999). To help combat this solitude and to meet the shifting demands of faculty work, collaborations should be encouraged (Austin \& Baldwin, 1991), particularly in the form of thinking communities which may help faculty sustain their passion for teaching and learning. The rewards of collaborative efforts such as thinking communities can be greater than the products generated. As Creamer (2004) noted, long-term collaborations can move faculty beyond individualistic 
thinking to global perspectives that challenge preconceived notions of knowledge and scholarship.

The changing dynamic of faculty work has the potential to discourage new entrants to the professoriate. Encouraging collaborations may be a way of repacking faculty work and keeping the initial spark that started individuals on the pathway to the professoriate. Reward structures for promotion and tenure need to be addressed, in particular for junior faculty, to lessen the unbalanced nature of the current faculty work role (Arreola et al., 2003). Organizationally, collaborative work should be encouraged. Current research on teaching and learning notes the benefits of cooperative and collaborative learning (Grant-Valone, 2011; Millis \& Cottell, 1997). These benefits should extend to faculty as learners as well. On an individual basis, collaborative work helps faculty reclaim their passion. On an organizational level, collaborative work can increase productivity, expand the knowledge base, and encourage diversity of thinking. Thinking communities and other types of collaborative work decrease faculty isolation, provide an outlet for idea generation, and encourage reflective practice which will benefit all aspects of faculty work. Ultimately, considering faculty as learners allows for a chance to reinvigorate passion within the professoriate and results in greater contributions to the knowledge base. 


\section{FIGURE 1}

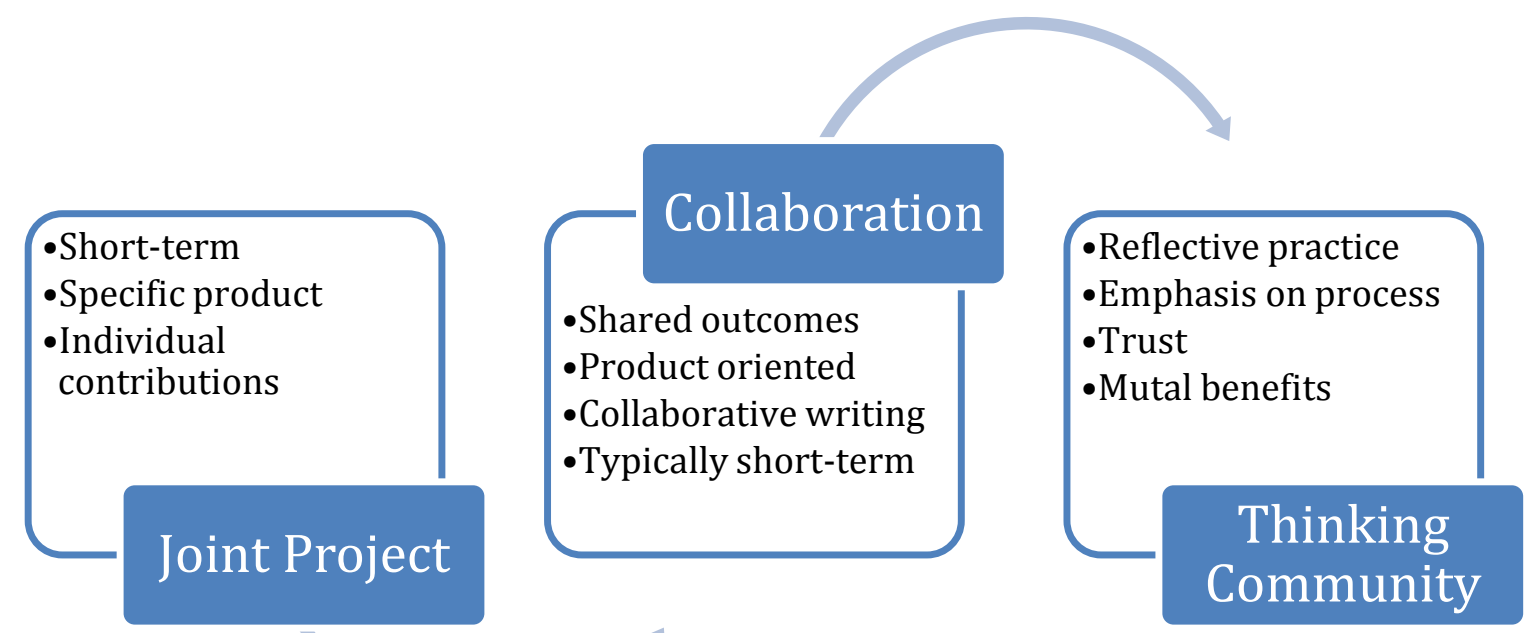




\section{References}

Amey, M. J., \& Brown, D. F. (2004). Breaking out of the box: Interdisciplinary collaboration and faculty work. Greenwich, CT: Information Age.

Argyris, C., \& Schon, D. (1978). Organizational learning: A theory of action perspective. San Francisco, CA: Jossey-Bass.

Arreola, R., Theall, M., \& Aleamoni, L. M. (2003, April). Beyond scholarship: Recognizing the multiple roles of the professoriate. Paper presented at the Annual Meeting of the American Educational Research Association, Chicago, IL.

Austin, A. E., \& Baldwin, R. G. (1991). Faculty collaboration: Enhancing the quality of scholarship and teaching. ASHE-ERIC Higher Education Report, no. 7. Washington, DC: School of Education and Human Development, George Washington University.

Boyer, E. L. (1987). College: The undergraduate experiences in America. New York: Harper \& Row.

Boyer, E. L. (1990). Scholarship reconsidered: Priorities of the professoriate. New York: The Carnegie Foundation for the Advancement of Teaching.

Brookfield, S. D. (1995). Becoming a critically reflective teacher. San Francisco, CA: JosseyBass.

Cox, M. (2004). Introduction to faculty learning communities. New Directions for Teaching and Learning, (97), 5-23.

Creamer, E.G. (2004). Assessing the outcomes of long-term research collaboration. Canadian Journal of Higher Education, 34, 24-41. 
Finkelstein, M. (1982, March). Faculty colleagueship patters and research productivity. Paper presented at the Annual Meeting of the American Educational Research Association, New York.

Flavell, J. H. (1976) Metacognitive aspects of problem solving. In L. B. Resnick (Ed.), The nature of intelligence (pp. 231-236). Hillsdale, NJ: Erlbaum.

Gappa, J. M., Austin, A. E., \& Trice, A. G. (2007). Rethinking faculty work: Higher education's strategic imperative. San Francisco, CA: Jossey-Bass.

Grant-Vallone, E. J. (2011). Successful group work: Using cooperative learning and team-based learning in the classroom. Journal on Excellence in College Teaching, 21, 99-121.

Hart, J., \& Mars, M. M. (2009). Joint appointments and the professoriate: Two houses but no home? Innovative Higher Education, 34, 19-32.

Hinck, S. S., Garza Mitchell, R. L., Williamson, P., Eddy, P. L., \& Bechtold, B. B. (2009, September). Reflection and research: Forming the perfect FIT. Teaching \& Learning: Journal of Natural Inquiry \& Reflective Practice, 23(3), 120-133.

John-Steiner, V. (2000). Creative collaboration. New York, NY: Oxford University Press.

Lattuca, L. R. (2001). Creating interdisciplinarity: Interdisciplinary research and teaching among college and university faculty. Nashville, TN: Vanderbilt University Press.

Lave, J. ,\& Wenger, E. (1991). Situated learning: Legitimate peripheral participation. Cambridge, UK: Cambridge University Press.

McGinn, M. K., Shields, C., Manley-Casimir, M., Grundy, A. L., \& Fenton, N. E. (2005). Living ethics: A narrative of collaboration and belonging in a research team. Reflective Practice, $6,551-567$. 
Menges, R. J. (1999). Faculty in new jobs: A guide to settling in, becoming established, and building institutional support. San Francisco: Jossey-Bass.

Mezirow, J., \& Taylor, E. W. (2009). Transformative learning in practice: Insights from community, workplace, and higher education. San Francisco, CA: John Wiley and Sons.

Millis, B. J., \& Cottell, P. G., Jr. (1997). Cooperative learning for higher education faculty. Series on higher education. Phoenix, AZ: Oryx Press.

Morgan, G. (2006). Images of organization. Thousand Oaks, CA: Sage.

Neumann, A. (2009). Protecting the passion of scholars in times of change. Change, 41(2), 1015.

O’Meara, K., Terosky, A. L., \& Neumann, A. (2008). Faculty careers and work lives: A professional growth perspective. San Francisco, CA: Jossey-Bass.

Pacarella, E. T., \& Terenzini, P. T. (2005). How college affects students: A third decade of research, Volume 2. San Francisco: Jossey-Bass.

Pifer, M. J. (2010). "Such a dirty word”: Networks and networking in academic departments. (Doctoral Dissertation). Available from ProQuest Dissertations and Theses database. (UMI No. 3420263).

Russ, S. L. (2010). Learning communities versus traditional courses: Which promotes the highest levels of student persistence, achievement, and integration? Little Rock, AR: The University of Arkansas at Little Rock.

Schon, D. (1983). The reflective practitioner: How professionals think in action. London, England: Temple Smith.

Schuster, J. H., \& Finkelstein, M. J. (2008). The American faculty: The restructuring of academic work and careers. Baltimore, MD: The Johns Hopkins University Press. 
Senge, P. M. (1990). Fifth discipline. New York: Doubleday.

Sorcinelli, M. D. (2000). Principles of good practice: Supporting early-career faculty. Guidance for deans, department chairs, and other academic leaders. Washington, DC: AAHE.

Sorcinelli, M. D. (2002). New conceptions of scholarship for a new generation of faculty members. New Directions for Teaching and Learning, 90, 41-48.

Sorcinelli, M. D., Austin, A. E., Eddy, P. L., \& Beach, A. L. (2006). Creating the future of faculty development: Learning from the past, understanding the present. Bolton, MA: Anker Publishing.

Wenger, E. (2006). Communities of practice: A brief introduction. Retrieved from http://www.ewenger.com/theory/communities_of_practice_intro.htm

Weissman, E., Butcher, K. F., Schneider, E., Teres, J., Collado, H., \& Greenberg, D. (2011). Learning communities for students in developmental math: Impact studies at Queensborough and Houston Community Colleges. New York: National Center for Postsecondary Research, Teachers College Columbia. 